\title{
A Colaboração no ensino do design: reflexões sobre aplicação em disciplina teórica.
}

\author{
The collaboration in the teaching of design: reflections on application in theoretical \\ discipline.
}

MORAES, Marina; Mestranda; Universidade Federal do Paraná

marinamoraes.design@gmail.com

BONIFÁCIO, Bruna; Mestranda; Universidade Federal do Paraná

bruna.c.bonifacio@gmail.com

HEEMANN, Adriano; Doutor; Universidade Federal do Paraná

adriano.heemann@gmail.com

CALOMENO, Carolina; Doutora; Universidade Federal do Paraná

carolcalomeno.ufpr@gmail.com

\section{Resumo}

Nos cursos de design os conceitos apresentados durante a graduação e as competências trabalhadas por docentes podem ampliar as percepções dos discentes acerca dos desafios práticos e teóricos da profissão. Este artigo tem como objetivo relacionar teorias e práticas colaborativas no âmbito acadêmico através da reflexão sobre a abordagem do tema em sala de aula. Como procedimento metodológico elaborou-se, primeiramente, uma revisão bibliográfica sistemática (RBS) em Anais do congresso P\&D dos temas gerais de colaboração e ensino. Em um segundo momento realizou-se um estudo de caso nos cursos de Bacharelado em Design e Tecnologia em Design Gráfico de uma instituição federal de ensino superior. Ao final, discute-se a análise dos trabalhos desenvolvidos na disciplina de Teoria e História do Design e suas reflexões acerca do processo de implementação de etapas do trabalho colaborativo.

Palavras Chave: colaboração, ensino em design, competências, design.

\section{Abstract}

In the design courses, the concepts presented during the undergraduate and the competences worked by the teachers can broaden the students' perceptions about the practical and theoretical challenges of the profession. This article aims to relate collaborative theories and practices in the academic context through reflection on the approach of the theme in the classroom. As a methodological procedure, a systematic bibliographic review (RBS) was first elaborated in Annals of the P\&D congress about the general topics of collaboration and teaching. In a second moment a case study was realized in the courses of Bachelor in Design and Technology in Graphic Design of a federal institution of superior education. At the end, we discuss the analysis of the work developed in the discipline of Theory and History of Design and its reflections on the process of implementation of stages of collaborative work.

Keywords: collaboration, teaching in design, skills, and design. 


\section{Introdução}

Refletir sobre a atuação profissional do designer passa por entender como se constrói a sua formação acadêmica. Nesse sentido os conceitos apresentados durante a graduação e as competências trabalhadas por docentes em seus conteúdos formativos podem ampliar as percepções dos discentes acerca de desafios práticos e teóricos da profissão. A complexidade dos projetos e a diversidade de possibilidades relacionadas a tecnologias ampliam a sua área de atuação e os inserem em um contexto multidisciplinar, no qual se faz necessário trabalhar com profissionais de áreas distintas. Essa comunicação entre áreas exige uma compreensão mútua acerca de conceitos e processos, além de um real entendimento sobre a construção de ferramentas e métodos colaborativos com abertura ao diálogo.

No âmbito acadêmico a divisão entre teoria e prática juntamente com a fragmentação dos conteúdos no ensino do design tem sido a tônica numa formação de caráter tecnicista, onde os discentes se preparam para a realização de uma atividade incentivados a desenvolvê-la através a competição com seus pares. Em contraponto, no mercado cresce a demanda de profissionais ligados a inovação de processos através da colaboração e da flexibilidade de competências comportamentais. Embora, como em todo processo contraditório, haja espaço para processos emancipatórios os discentes que se colocam nesse lugar de entender as habilidades necessárias para atuar nesse novo cenário profissional costumam buscar fora da universidade essa mediação entre aquisição de conhecimento e a sua materialização em ações transformadoras.

O ensino de design pode contribuir significativamente para preparar os discentes para as novas demandas de inovação, através de uma configuração que efetivamente articule conhecimento científico e conhecimento tácito. Esse artigo tem como intenção relacionar referenciais teóricos e atividade prática que possibilite a reflexão sobre o ensino e a aplicação da melhoria na colaboração do design em sala de aula. O estudo de caso foi realizado no ano de 2017 em uma disciplina ministrada para discentes do curso de Bacharelado em Design e Tecnologia em Design Gráfico de uma instituição federal de ensino superior com a participação de duas turmas, totalizando cerca de 50 discentes. A disciplina Teoria e História do Design 2 é ministrada no quinto período curricular.

A disciplina em questão tem um caráter teórico de investigação da história contemporânea do design através de um viés social e filosófico da pós-modernidade. Trabalhando com autores como Baudrillard (1991), Gruszynski (2000), Bauman (2001) e Cardoso (2008), a produção e orientação dos trabalhos se desenvolveram durante dois meses na disciplina, totalizando seis encontros. 0 presente artigo tem como intenção apresentar as discussões e reflexões acerca do processo de trabalho nesse período e as reflexões teóricas acerca do tema de melhoria da colaboração no ensino de design dentro desse contexto.

Para Rafael Cardoso (2008) o objetivo do estudo da história do design é o de ampliar os horizontes, sugerindo soluções criativas para o presente com base nos exemplos do passado. Assim, a análise dos trabalhos se deu não apenas através de suas narrativas visuais, mas baseado em referências históricas e no próprio contexto pós-moderno atual, levando em consideração a importância do intercâmbio de informações como forma de construção narrativa da história. 


\section{Método}

Para o desenvolvimento do embasamento teórico sobre a colaboração no ensino do design foi empregada como ferramenta a Revisão Bibliográfica Sistemática (Conforto, Amaral e Silva, 2011) com a busca de artigos em Anais do P\&D (Congresso Brasileiro de Pesquisa e Desenvolvimento em Design) disponíveis para acesso online. Assim sendo, os Anais de 2012, 2014 e 2016 compõem a fonte de busca, na qual as strings "ensino", "educação", "colaboração", "cooperação" e "cocriação" foram aplicadas, resultando em 1 artigo no P\&D 2012, 2 artigos no P\&D 2014 e 8 artigos no P\&D 2016, os quais foram lidos na íntegra, e na sequência 4 foram selecionados. Os 4 aprovados para a etapa de análise compõem a síntese temática das publicações e referências bibliográficas para esta escrita. Da mesma forma, como embasamento dos conceitos da disciplina, foram utilizados os autores de referência da disciplina de Teoria e História do Design 2 no qual os discentes realizaram a análise e entendimento de conceitos abordados na ementa do curso.

Após o levantamento do referencial teórico foi desenvolvido um estudo de caso nos cursos de design de uma Universidade Federal, na cidade de Curitiba-PR, no segundo semestre do ano de 2017. As atividades foram realizadas no período de seis semanas, na disciplina de Teoria e História do Design II com duas turmas do quinto período, totalizando cerca de 50 discentes. A realização da atividade buscava a aplicação e entendimento de métodos e conceitos do design colaborativo como forma de compreender melhor os desafios enfrentados no contexto de sala de aula.

$\mathrm{Na}$ primeira etapa foi estruturada a proposta de análise teórica dos trabalhos, foi estabelecido como critério de escolha projetos realizados durante o período da graduação, mas não obrigatoriamente na instituição de ensino. Devido a uma porcentagem de discentes da turma realizarem intercâmbio, através do programa de ciências sem fronteiras do governo federal, houve o interesse em apresentar resultados desse período, ampliando os cenários de discussões de conceitos através da visão do design em outros contextos culturais. Além disso, também se possibilitou a seleção de trabalhos nos quais existissem admiração e vínculo com o processo criativo.

Na segunda etapa estes trabalhos foram entregues para discentes da turma, para análise teórica, os quais receberam somente as imagens dos projetos e um breve parágrafo de contextualização. Em duplas ou trios os grupos geraram um texto de 3 a 5 páginas, com formatação de texto científico e inserção da fundamentação teórica. Como forma de auxiliar no entendimento dos conceitos a serem abordados houve duas reuniões de orientação com a professora e discussões acerca do andamento do texto e suas possíveis abordagens de bibliografia e conceitos. Nessas reuniões também foi possível conectar informações e ampliar a visão acerca dos objetivos da atividade. No último estágio houve a entrega dos textos e apresentação dos trabalhos através de um debate com o tema: "Quais os ganhos de pensar a colaboração no design dentro contexto contemporâneo?".

A Figura 1 apresenta os objetivos principais de abordagem da aprendizagem nessa atividade. Os estágios do processo percorridos pelos discentes serão abordados com mais detalhes no capítulo 3.2.1 (Aplicação do conceito de colaboração em sala de aula), além dos comentários dos resultados alcançados no decorrer do processo no 3.2.2 (Resultados alcançados). 


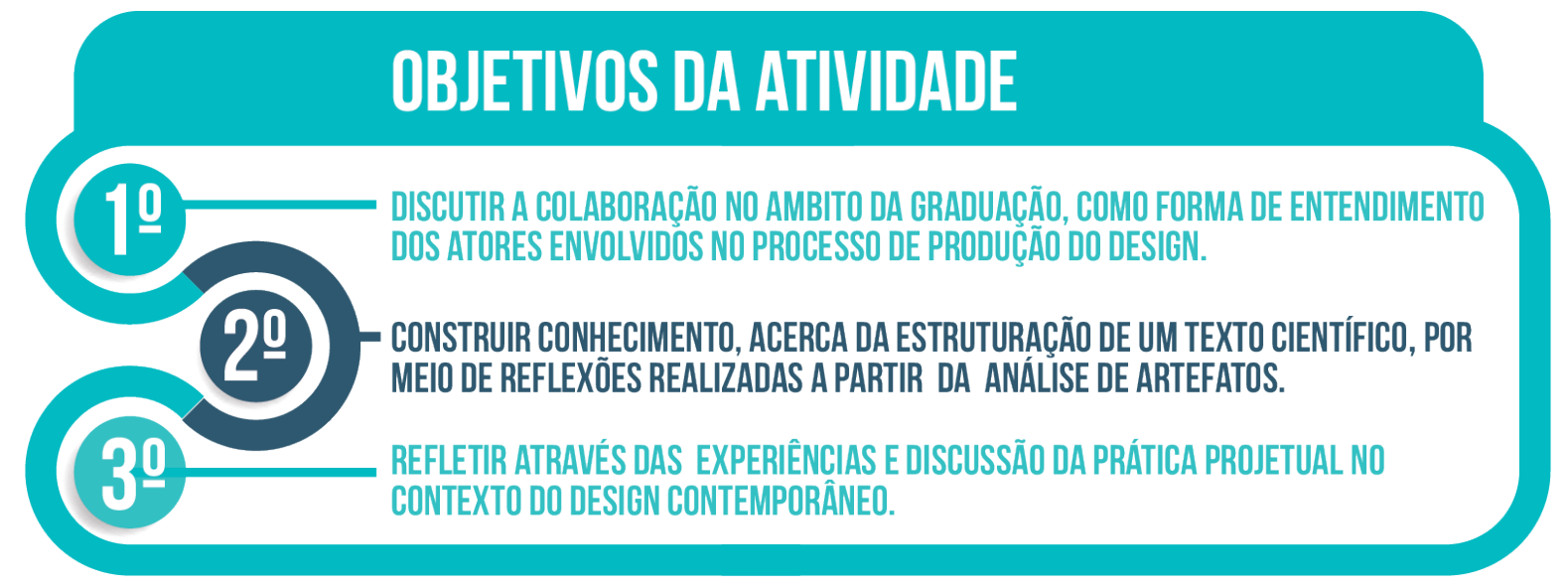

Fonte: Autores (2018)

\section{Desenvolvimento}

\subsection{O Papel do professor como mediador do conhecimento através da colaboração.}

O ambiente acadêmico historicamente se estrutura na figura do indivíduo, através do mito do autor, no qual "a explicação da qualidade da obra fica circunscrita à trajetória biográfica do sujeito, apresentando-se como expressão da sua criatividade individual" (SANTOS, 2015, p. 26). Em seu texto, Santos (2015) traz Forty (2007) e Campi (2003) para mostrar que o mito de "autonomia criativa" desloca o designer do contexto do qual ele faz parte - desconsiderando elementos socioculturais, econômicos e políticos - e o coloca como protagonista único - deixando invisíveis as contribuições e participações de atores sociais e parceiros, assim como seu reconhecimento na divulgação posterior dos projetos. Essa perspectiva do design como "a relação entre a mente do designer e a forma do objeto projetado" (FORTY, 2007, p. 324) é apenas uma das maneiras de se pensar sobre o design, e vêm sendo questionada e problematizada.

Na mesma linha de raciocínio Forty (2007) apresenta uma reflexão através do modo de expor os projetos de design por meio de uma leitura das bibliografias dos projetistas, como se um produto de design estivesse sempre relacionado a figura de um indivíduo e sua narrativa histórica. Ele denomina como "ênfase da pessoa do designer" trabalhos e projetos que são realizados em equipe são expostos em museus e exposições sem creditar todos os atores do processo criativo.

Em 1979, por exemplo, o Conselho de Artes da Grã-Bretanha montou uma grande mostra na galeria Hayward, em Londres, sob o titulo "Anos Trinta", na qual exemplares da arte, arquitetura e do design britânico da década de 1930 foram exibidos. A maioria dos artefatos foi evidentemente selecionada por sua conformidade a um estilo que se acreditava ser o daquela década, e as informações das legendas davam o nome do designer, o nome do fabricante, a data do design e o nome do dono atual. A única informação adicional fornecida pelo catálogo da exposição era uma curta biografia de cada designer citado. A partir dessas informações, o visitante da exposição concluiria naturalmente que o mais significativo era saber quem desenhou o objeto. (FORTY, 2007, p. 322)

A ausência das informações e a invisibilidade dos outros participantes dos projetos fizeram com que os autores e historiadores de design, através da sua escrita, colocassem o designer como foco principal do processo de fabricação dos produtos, ficando difícil de distinguir no ensino e na 
prática que os projetos não eram apenas expressões da criatividade do designer e que o envolvimento desse profissional com o processo de produção se fazia tão importante quanto seu envolvimento com o processo criativo. Além disso, a criação de um mercado de design onde a autoria encarece o produto ampliou essa divulgação nominal durante décadas na história do design. Esses aspectos, entre outros, provocaram uma necessidade de associação ao registro autoral de produtos a história do design. No ensino do design isso se propagou por gerações nas quais a concorrência entre alunos era socialmente alimentada, pois poucos nomes seriam registrados na lista dos grandes designers. Além dos processos criativos serem mantidos em sigilo devido a escassez de mercado e de áreas diversas de atuação (FORTY, 2007).

Para Santos (2015, p.2) “a maneira pela qual a história é contada configura uma espécie de lente pela qual olhamos o design". Assim, na aula de teoria e história do design, os professores com base no referencial teórico da disciplina ampliam e dão foco para o que será abordado durante o semestre e o aluno tem como oportunidade repensar os fatos históricos através de uma nova ótica que promova uma reflexão crítica sobre o conteúdo apresentado. Estudar conceitos como autoria, colaboração em equipe e construção coletiva de processos ampliam a compreensão dessa fronteira com a autonomia criativa do designer, suas etapas de produção e os atores da execução. Assim como possibilitam compreender como acontece a variação de processos e gestão do design no decorrer da história da produção industrial.

A criatividade e autonomia são necessárias, mas em um âmbito geral contemporâneo é importante entender a relevância da formação do designer em um mundo globalizado com crises ecológicas e mudanças rápidas de meios e modos de comunicação, comportamento e áreas de atuação. Nesse contexto a sala de aula tem se tornado um ambiente que busca estar em conformidade com a velocidade das relações que se estabelecem culturalmente. Os docentes se encontram cada vez mais em um meio dinâmico, no qual necessitam ter habilidades de gerenciamento de crises e contribuir na construção de ambientes propícios ao estabelecimento de relações, ainda durante a graduação, como forma de exercitar essas competências no decorrer do ensino e aprendizagem.

Para Heemann et al. (2008) precisa-se entender a Colaboração no Design como uma ferramenta transformadora e integradora de todo processo de projeto. Para isso primeiro é necessário distingui-la de termos como "reciprocidade obrigatória", "interação" e "realização simultânea" pois essas questões podem se dar também em um ambiente hostil. Dessa forma não necessariamente são direcionados de maneira a entender as relações entre os atores do processo e sua participação essencial no desenvolvimento dos projetos e dos agentes de integração. Dentro de um processo de colaboração em etapas de design os integrantes necessitam estar comprometidos com todo o procedimento a ponto de se sentirem parte da construção dessas etapas.

Especificamente no campo do design, aponta para uma ênfase em habilidades e atitudes como empatia, colaboração, liderança e aprofundamento cultural, consideradas hoje mais relevantes que o conhecimento puramente técnico. Dadas essas exigências do mercado não-acadêmico, cabe à academia formar um profissional capaz de atender a elas. Entretanto, acredita-se que não são apenas as exigências mercadológicas, enquanto referências, que podem contribuir para o ensino superior em design - abordagens inovadoras utilizadas na prática do design também podem ser re-contextualizadas para a educação. (Heemann e Lugli, 2016, p.2201). 
Heemann e Lugli (2016), investigam uma abordagem educativa denominada Studentcentered learning (SCL) que privilegia o estudante ao invés do professor ou do conteúdo. "É baseada na teoria construtivista da aprendizagem, que afirma que o aprendizado ocorre de maneira mais efetiva quando as experiências do próprio estudante são capazes de gerar um produto significativo" (HEEMANN, LUGLI; p.2, 2016). Ela parte do pressuposto que o estudante identificando a proposta no seu cotidiano fica mais disposto a assimilar conhecimento através de um processo contínuo de transformação. Na abordagem apresentada pelos autores o aluno possui autonomia e se baseia em teorias humanistas da educação, que indica que o aprendizado deve considerar o indivíduo como um todo. Eles afirmam que frequentemente essas abordagens são utilizadas no ensino básico, mas seus princípios e usos vêm crescendo no ambiente da graduação, trazendo autonomia para o estudante no que se reflete ao comportamento profissional.

Como mediador e facilitador dessas práticas o professor desenvolve uma conexão com os alunos, suas vivências e seus conhecimentos acerca do conteúdo da sua disciplina e de relações que podem se integrar nesse processo. Em décadas de ensino do design formaram-se profissionais com base em conceitos estabelecidos em competências através da concorrência, em reflexo a uma cultura econômica de mercado. Nesse momento histórico com escassez reais de recursos e oportunidades formalizadas de trabalho, esse posicionamento de valorizar processos de integração entre equipes multidisciplinares favorece a participação do aluno em outras frentes de atuação profissional. Ansastassakis e Paes (2016) apresentam como historicamente se iniciou essa abordagem de fornecer recursos para que todos os parceiros do projeto trabalhem como forma de obter sucesso na execução dos processos de maneira colaborativa e participativa:

\begin{abstract}
Entre o final do século XIX e início do século XX, o design escandinavo caracterizava-se pela forte influência da tradição do artesanato e pelo uso eficiente de recursos naturais limitados. Enquanto nestes países (Noruega, Dinamarca e Suécia) o processo de industrialização tardou mais a se estabelecer do que nos Estados Unidos e outros países da Europa, as teorias sociais de John Ruskin, William Morris e do Movimento Arts\&Crafts se espalharam rapidamente pela Escandinávia e Finlândia. Mais ainda, em 1845, foi criada a Sociedade Sueca de Desenho Industrial, como forma de defender e sustentar elevados padrões em várias profissões relacionadas ao artesanato (EYPÓRSDÓTTIR, 2011). A partir da iniciativa do movimento Arts\&Crafts em integrar os processos derivados do artesanato com a produção comercial e, justamente levando em conta a criação de diversas instituições e escolas em prol de preservar a tradição do artesanato após a 2a Guerra Mundial, torna-se mais clara a compreensão de como se consolidou o modelo finoescandinavo de design. (ANSASTASSAKIS, P, 2016, p. 940).
\end{abstract}

No Brasil a história do design se estruturou de maneira diferenciada por conta da influência de escolas alemãs como a Bauhaus e a escola de ULM, de abordagem industrial modernista. Nos últimos anos as redes de comunicação e informação potencializaram o conceito de colaboração e participação e possibilitaram a apropriação do discurso por parte de sistemas ainda baseados em "comando e controle". Algumas iniciativas que atraem pessoas, profissionais ou estudantes, utilizam-se deste conceito de colaborar com um propósito ou projeto, oferecendo baixa remuneração ou risco, seguindo um modelo estruturado em dominação e exploração. Por essas questões de posicionamento e entendimento da construção profissional se faz necessário abordar e entender o tema ainda no período da graduação. Estabelecer um ambiente de trabalho colaborativo depende da relação das pessoas envolvidas, da confiança entre elas e da dedicação de construir um projeto no qual todos sejam parte e responsáveis pela qualidade final. 


\subsection{Estudo de caso}

\subsubsection{Aplicação do conceito de colaboração em sala de aula}

Como forma de desenvolver um exercício de autocrítica e estruturar um pensamento de integração e colaboração entre os alunos em uma disciplina de graduação - Teoria e História do Design 2 - foi elaborada uma atividade em parceria entre duas professoras da disciplina. Esse artigo é uma reflexão e análise da segunda aplicação desse mesmo trabalho realizado no segundo semestre de 2017, em duas turmas no curso de Bacharelado em Design e Tecnologia em Design Gráfico no contexto de uma universidade pública federal localizada na cidade de Curitiba, estado do Paraná, na região sul do Brasil.

No ambiente de sala de aula a aceitação dos discentes as atividades propostas não se comportam de maneira linear e os cenários não podem ser previstos com exatidão, os alunos aprendem a lidar com a complexidade e entender que o contexto é passível a transformação. Esse aspecto se apresenta desafiador para professores, como forma de motivar e orientar o processo para a abertura e o fechamento de atividades em sala com clareza e foco. A liberdade criativa se não for bem dirigida e orientada pode levar a frustação, natural do processo de aprendizado, principalmente quando alguma etapa não sai como planejado. Devido a isso vale ressaltar a importância das reuniões de orientação e de um roteiro estruturado como forma de conduzir a prática e as orientações no decorrer do processo, entendendo como delimitar a integração dos grupos ao envolvimento em todas as etapas, assim motivando a realização das atividades e resolução de conflitos.

Durante o semestre, foram estudados períodos da história do design moderno e pósmoderno com base no seu contexto histórico, artístico e social. Segundo os autores referenciados na disciplina, designers e artistas podem ser categorizados em diferentes escolas e grupos de acordo com suas ideologias e influências estéticas. Muitas vezes essas categorizações são realizadas posteriormente por historiadores, críticos de arte e pesquisadores.

Um questionamento habitual dos discentes no processo de aprendizagem nessa disciplina é como funciona a escrita da história e de que maneira o julgamento de "bom design" proposto pelo designer Diter Rams, um dos precursores do Estilo Internacional no século XX, se propaga até hoje como modelo em disciplinas práticas na instituição de ensino na qual o estudo de caso foi realizado. Santos (2015) apresenta um pouco mais esse contexto histórico de implementação do Estilo Internacional:

No que concerne à linguagem, o projeto de modernização capitalista baseado na industrialização estimulou identificações com a vertente funcionalista denominada Estilo Internacional, que se consolidava como tendência na Europa e nos Estados Unidos. Tendo como preceitos a otimização da produção e a ênfase na funcionalidade, o Estilo Internacional primava pela abstração das formas mediante a geometrização dos volumes e a supressão de ornamentos; pela transparência da composição estrutural; e pelo emprego de elementos modulares ou padronizados (ARGAN, 1992). Essas diretivas eram defendidas como meios para alcançar padrões "universais", decorrentes de deduções lógicas pautadas em exigências objetivas. (SANTOS, 2015, p.5).

Um dos objetivos da ementa da disciplina (Quadro 1) é refletir sobre o design mundial e o design brasileiro como construções sociais e históricas no final do Séc. XX início do Séc. XXI; como forma de pesquisar e analisar artefatos observando as interações culturais e estilísticas, além de ampliar o entendimento sobre o processo de produção no âmbito do design. 
Quadro 1. Ementa da disciplina de Teoria e História do Design 2

\begin{tabular}{|c|c|c|c|}
\hline Item & Ementa & \multicolumn{2}{|l|}{ Conteúdo } \\
\hline \multirow{3}{*}{1} & \multirow{3}{*}{$\begin{array}{l}\text { Relações entre Design e } \\
\text { cultura, constituídas } \\
\text { historicamente, no Brasil e } \\
\text { no mundo; a história do } \\
\text { Design no contexto do } \\
\text { desenvolvimento das } \\
\text { sociedades industriais e pós- } \\
\text { industriais; conceitos, } \\
\text { valores e questões do Design } \\
\text { presentes nos movimentos e } \\
\text { escolas de Design, dos anos } \\
60 \text { à contemporaneidade. }\end{array}$} & $\begin{array}{l}\text { 1. Design e cultura, } \\
\text { constituídas historicamente, } \\
\text { no Brasil e no mundo. }\end{array}$ & $\begin{array}{l}\text { - O alcance do Estilo Internacional } \\
\text { - A contribuição dos Estados Unidos } \\
\text { - Repercussões da Escola de Ulm } \\
\text { - A formação do design moderno no } \\
\text { Brasil } \\
\text { - Design na América Latina }\end{array}$ \\
\hline & & $\begin{array}{l}\text { 2. A história do Design no } \\
\text { contexto do } \\
\text { desenvolvimento das } \\
\text { sociedades industriais e pós- } \\
\text { industriais. }\end{array}$ & $\begin{array}{l}\text { - Kitsch versus vanguarda } \\
\text { - Pop design, psicodelia } \\
\text { - Design e a Era espacial } \\
\text { - O pop design no Brasil } \\
\text { - Design e protestos sociais }\end{array}$ \\
\hline & & $\begin{array}{l}\text { 3. Conceitos, valores e } \\
\text { questões do Design } \\
\text { presentes nos movimentos e } \\
\text { escolas de Design, dos anos } \\
60 \text { à contemporaneidade. }\end{array}$ & $\begin{array}{l}\text { - Anti-design, Radical design: grupos e } \\
\text { movimentos italianos } \\
\text { - Estética Punk } \\
\text { - Pós-modernismo } \\
\text { - Desconstrutivismo } \\
\text { - Memphis } \\
\text { - Design e cybercultura } \\
\text { - Tendências do design contemporâneo } \\
\text { - Design brasileiro contemporâneo }\end{array}$ \\
\hline
\end{tabular}

(Fonte: Ementa dos cursos-Departamento de Design)

$O$ ato da crítica, de maneira estruturada e reflexiva através do referencial teórico encontra resistência dos discentes em um primeiro momento e não escapa nem da polêmica de assuntos vistos anteriormente e nem das dificuldades de estabelecer relações entre autores que podem ser articuladas para construção do texto analítico. Outro aspecto é o medo de se expor em sala de aula durante os debates e discussões. Como forma de construção do aprendizado esse incômodo e oposição a fruição da escrita e do pensamento estruturado foi trabalhado o interesse dos discentes em avaliar e serem avaliados, através de uma prática de colaboração na construção teórica.

No processo de estruturar e refletir sobre a atividade a ser ministrada foi definido que seria importante apresentar para os discentes o trabalho de análise de um produto de design no qual eles tivessem participado do processo de criação e entendessem de todas as etapas. Seria discutido e apresentado no semestre a proposta de design contemporâneo e os discentes como representantes dessa produção seriam preparados a perceber quais são as características do seu trabalho de design e onde se encontram na produção atual.

O texto foi realizado em duplas ou trios, pois visava impulsionar a leitura e reflexão sobre a produção além de apresentar para os alunos a integração entre as atividades teóricas e práticas resultantes do processo de ensinar, pesquisar, aprender e avaliar o processo criativo após algum tempo de realização. Os grupos se formaram de maneira livre quanto a escolha dos participantes, mas foram orientados a perceber qual era o estilo de trabalho do outro integrante da equipe, como forma de motivar o aluno a uma pesquisa em uma área do seu interesse. Esse critério foi trabalhado com mais efetividade nas turmas de bacharelado em design, nas quais o aluno tem uma formação 
generalista e não se aprofundam em áreas específicas do design. Assim trazendo referenciais e designers extras ao que foram propostos em sala de aula.

Os alunos tinham como proposta criar uma linha narrativa estruturada nas referências da história do design. Tendo acesso ao autor do projeto, puderam questionar sobre o processo criativo aplicado. Essa troca de análise possibilitava também receber um retorno teórico acerca da sua produção, assim podendo refletir sobre aspectos que nem sempre são levados em consideração no ato de projetar. $O$ aluno estando motivado a responder essas questões possibilitava estar livre de julgamentos ou elevações com relação a qualidade técnica da sua produção, pois apresentava um caráter contextual e não prático imediatista de análise.

Se o design atualmente se apresenta multifacetado pela confusão entre produtos, métodos e objetivos é recomendável averiguar as janelas que o circundam antes de tomar para si uma visão única. Sendo assim, e reconhecendo a dimensão inerentemente retórica que todo o pensamento em design carrega, Buchanan (1995) demonstra que é justamente a forma de observar que caracteriza e define o design. (ANSASTASSAKIS, P, 2016, p. 940)

O designer utiliza seu conhecimento e sua bagagem cultural para a produção de seus trabalhos e não é raro haver referências a certos movimentos do design no próprio briefing do projeto. Da mesma forma também é muito frequente que o trabalho seja desenvolvido sem o autor tomar consciência de suas decisões, sem base de referências específicas. O objetivo deste trabalho foi simular didaticamente o papel de historiadores e críticos de arte ao analisar teoricamente projetos de outros integrantes da turma. Um olhar de fora pode ser eficaz para identificar influências que ao próprio autor do trabalho podem ter passado despercebidas no desenvolvimento do processo criativo.

Como estrutura do trabalho final da disciplina os alunos deveriam:

1. Selecionar 3 projetos desenvolvidos no decorrer da vida acadêmica, dentro ou fora da instituição de ensino.

2. Apresentar e enviar a sua seleção para a sua dupla ou trio.

3. Analisar textualmente o trabalho do colega segundo as suas referências visuais: slides apresentados nas aulas expositivas e embasamento bibliográfico da disciplina GRUSZYNSKI, (2000) e CARDOSO (2008). Assim como a sua produção no contexto do design contemporâneo.

4. Em dupla discutir e correlacionar a sua produção com o trabalho do colega.

5. Trazer o resultado das discussões para a orientação com a professora.

6. Produção de um texto de 3 a 5 páginas apresentando as análises assim como as referências e narrativas que permeiam os projetos.

7. Trazer a produção textual para a orientação com a professora.

8. Desenvolvimento da conclusão: Estabelecer relação ou diferenciação entre os seus trabalhos e do seu colega.

9. Apresentação dos resultados em sala de aula no formato seminário para discussão com os outros grupos (10 min de apresentação)

Com o contexto definido e apresentado, os grupos se aprofundaram na busca de dados que permitissem intensa reflexão acerca dos problemas levantados na proposta, além de uma boa compreensão da situação de desenvolvimento dos projetos que seriam analisados. Os encontros e 
orientações tinham como objetivo gerar alternativas de soluções que fossem mais adequadas ao contexto. Os estudantes estavam em diversos estágios da graduação, apesar da disciplina ser ministrada no quinto período a universidade permite que alunos de outros períodos se matriculem. No início esse aspecto parecia um agravante para o desenvolvimento do trabalho autônomo em equipe, mas se mostrou um caráter motivador a integração de diversos níveis de conhecimento e aprendizado mútuo no decorrer das reuniões.

Essa estrutura da aplicação por se tratar de uma abordagem empírica exige ainda alguns desafios na ampliação da abordagem teórica e avaliação estruturada dos seus resultados em outras aplicações em trabalhos futuros.

\subsubsection{Resultados alcançados}

Analisando o papel do professor universitário como sujeito de transformação e aprendizado, o presente artigo buscou refletir sobre essa construção teórica e processo de atuação em sala de aula. Assim conectando o conteúdo, relacionado a ementa de uma disciplina a atividades de análise teórica com as vivências projetuais dos alunos no decorrer do curso de graduação. Além da identificação do aluno no seu contexto cotidiano como forma de construção do seu aprendizado.

No início do processo de seleção dos projetos a maioria dos discentes apresentou dificuldades de escolha dos seus trabalhos, alguns narraram a falta de confiança com relação a qualidade técnica ou responsabilidade com o processo. Outros tiveram dúvida com relação a ter uma referência direta com algum movimento histórico do design, ou ter um conceito estruturado bem fundamentado no trabalho. Mas orientou-se que todos os projetos independentemente da sua qualidade técnica ou conceitual poderiam ser analisados e discutidos.

Na semana seguinte da reunião de apresentação da proposta, os alunos trouxeram imagens e registros dos seus projetos favoritos. Nesse momento percebeu-se que teria que se trabalhar a autocrítica e confiança com relação ao que seria analisado, pois muitos deles não estavam confiantes com relação ao seu portfólio, apesar de constar excelentes trabalhos. Nessa reunião foi trabalhado o tema que Gruszynski (2000) aborda como generalização de um período histórico. Quando se tratava da discussão da pós-modernidade a autora suscita a seguinte pergunta: "Como generalizar um período que descrê nas generalizações? ". Ela define essa como o fim das grandes narrativas e a valorização das pequenas narrativas, da individualidade e da pluralidade. Assim, sem um pensamento dominante, os movimentos se tornam cada vez mais heterogêneos e para construir sua análise a autora opta por utilizar o conceito etimológico da palavra, considerando como pósmoderno tudo que sucede a modernidade.

No total foram apresentados mais de 100 projetos, criando um panorama de suas preferências e potencialidades dentro do curso de design, cada dupla ou trio apresentou uma média de 5 trabalhos e suas relações de similaridade ou contraste entre os 14 grandes temas de abordagem. Temas esses que podem ser vistos na Figura 2, com a sistematização das etapas de trabalho e seus resultados:

Figura 2. Sistematização das etapas do trabalho. 


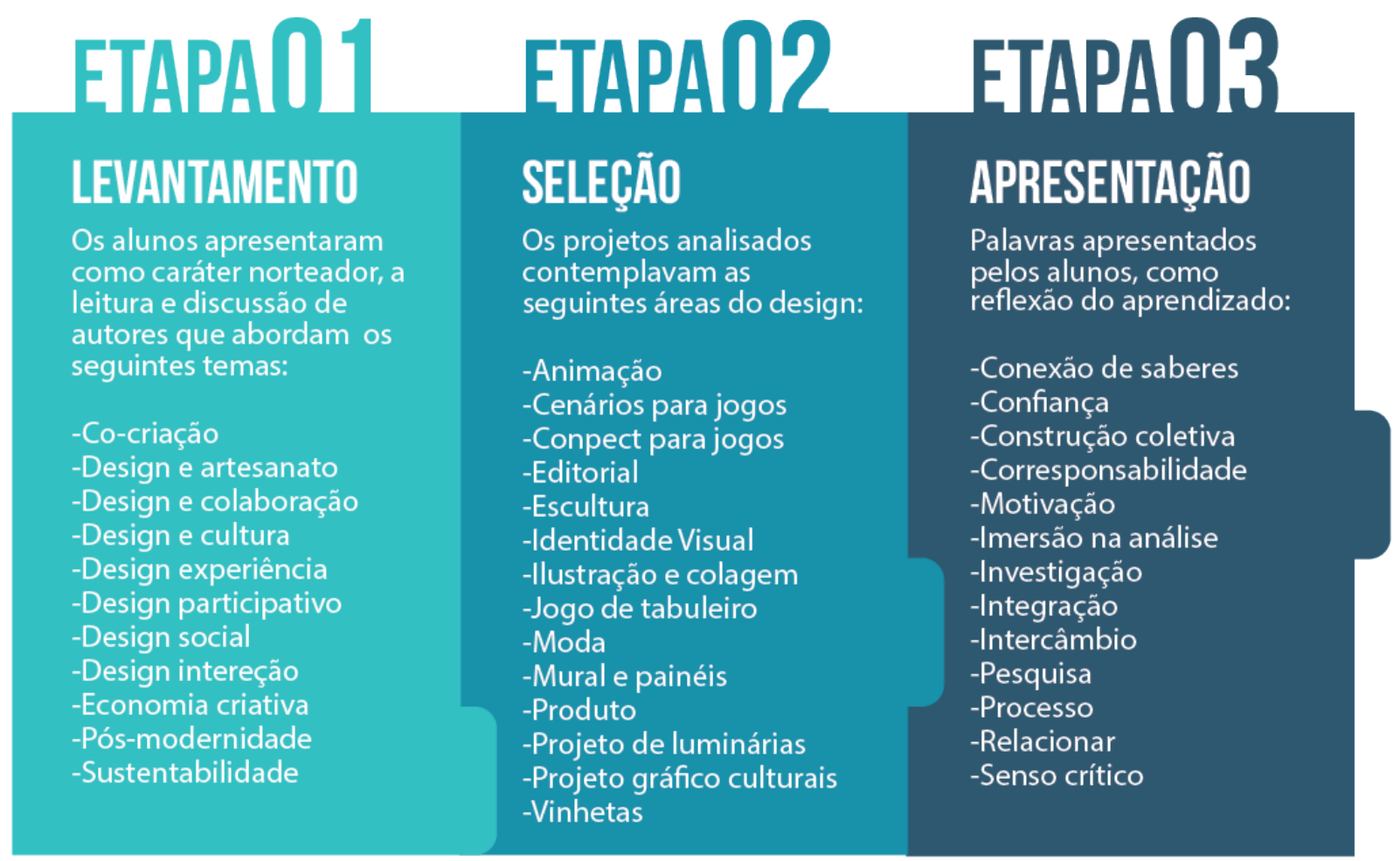

Fonte: Autores (2018)

Os alunos fizeram um exercício coletivo de utilizar termos e definições fundamentais para mergulhar em autores que pudessem ir além do design modernista. Nesse levantamento surgiram várias relações interessantes dos trabalhos com conceitos contemporâneos do design que podem ser observados na etapa 01 da figura 2. No que se refere a estrutura da retórica e do uso da teoria na construção prática do design as autoras Ansastassakis e Paes (2016) abordam que a libertação do processo fabril de construção de larga escala, justificado por um consumo excessivo e uma produção intensa, só foram repensados a partir da ação intelectual do design e a formulação do pensamento crítico sobre a produção que estava sendo desenvolvida através do pensamento científico e do avanço da pesquisa em processos e métodos do design.

De tal maneira o exercício do aluno observar o seu trabalho com atenção e olhar para o do colega com o devido respeito incentiva também desenvolver aspectos do design colaborativo como a participação do usuário na construção coletiva do design, a abertura de seus processos criativos como forma de melhoria e reflexão sobre o resultado final. Os alunos se mantiveram motivados durante todas as reuniões de orientação perguntando e questionando sobre os textos que teriam que ler para relacionar com o conteúdo, perceberam no decorrer do caminho que sem a leitura seria muito difícil estruturar o trabalho através de um pensamento crítico. Foi comum a prática de uso de textos complementares para a discussão, como forma de localizar a análise na produção contemporânea, assim abordando conceitos como design e artesanato, arte contemporânea, instalação urbana entre outros aspectos de fronteira da arte com o design.

Alunos que não possuíam a prática de leitura e escrita apresentaram o exercício passo-apasso como forma de evolução do texto e engajamento com o processo de construção textual e conseguiram apresentar de maneira estruturada sua linha de raciocínio. $O$ trabalho em grupo também foi uma surpresa para os alunos no processo, pois eles relataram que passaram por muitas 
frustações durante a graduação através da constituição de grupos por afetividade ou sorteio pelos professores. O fato deles se conectarem pelo tema de discussão possibilitou um profissionalismo nas relações e um interesse maior na estruturação da proposta.

Outro aspecto interessante do levantamento foram os discentes que trabalharam com projetos realizados através do intercâmbio pelo programa ciência sem fronteiras, os quais apresentaram reflexões diretas acerca do trabalho colaborativo, dessa maneira esses relatos foram selecionados para serem descritos no presente artigo. Surgiram nos textos e apresentações conexões com diversos países como Moçambique, EUA, Alemanha e Canadá.

A Integração e corresponsabilidade em todas as etapas do projeto, foi analisada através do trabalho online e os desafios para o seu desenvolvimento. Um dos projetos apresentados nessa abordagem foi o realizado a distância, para uma empresa nos EUA. O trabalho foi desenvolvido de forma colaborativa; participaram do projeto uma designer, que trouxe o conceito e imagens de referência para a peça; a dona da empresa e a designer responsável pelo protótipo. $O$ cargo da aluna foi o de ser a ponte entre a designer e a fábrica, traduzindo as ideias iniciais da cliente para um desenho com as especificações técnicas necessárias para que o produto pudesse ser desenvolvido.

O processo de avaliação desse trabalho como um todo foi pensado como forma de incentivar a pesquisa sem a recompensa. A nota não foi dividida individualmente e os alunos precisavam estabelecer integração como forma de obter nota da equipe. Posterior à avaliação e reflexão sobre o processo foi pensado que a auto avaliação pudesse atender melhor a expectativas dos alunos com relação ao seu desenvolvimento intelectual no decorrer da proposta. Para aplicações futuras serão levadas considerações nesse aspecto.

\section{Conclusão}

Este estudo tratou do levantamento de publicações sobre possibilidades de práticas colaborativas no ensino de design na graduação, por meio de uma Revisão Bibliográfica Sistemática (RBS) realizada nos Anais do P\&D disponíveis online, com o objetivo de fomentar o ensino e aprendizado colaborativo no design. Foi possível encontrar publicações acadêmicas com diferentes linhas de pesquisa, proporcionando um breve panorama da literatura, que auxiliou nas reflexões aqui apresentadas. Além da aplicação do estudo de caso em sala de aula, em cursos de graduação em Design em uma disciplina de Teoria e História do Design.

Apesar da universidade na qual foi aplicado o estudo de caso ter sua matriz curricular estruturada no referencial e princípios do design modernista ficou evidente as características pósmodernas dos trabalhos analisados pelos alunos. A inserção dos alunos em um mundo onde vivem bombardeados de informações constantes, a internet, novas formas de interação, fazem com que suas visões perpassem ao que é apresentado na universidade, não se atendo às restrições e normas rígidas da sala de aula. Essa geração do final do século XX, que teve a televisão e o controle remoto - símbolo da rapidez e superficialidade - desde seu nascimento trabalham e abordam o design de maneira dinâmica, as propostas de trabalho em sala também necessitam se encaminhar de encontro para sensibilizar esse processo de aprendizado. Como forma de reconhecimento da teoria pelo aluno e o interesse de buscar construir um pensamento crítico alheio a superficialidade de internet. 
Repensar e refletir essas formas de interação e produção é muito importante para que o design inove em propostas de estéticas e processos, aproveitando-se do dinamismo, mas construindo o conhecimento com base sólida nos teóricos e historiadores. A principal característica percebida na análise dos trabalhos foi a presença de referências a movimentos pré-existentes, mas moldadas pelo contexto pós-moderno. Mesmo que os trabalhos pertençam à diferentes áreas do design (design gráfico, ilustração, design de produto, design de moda...) e tenham inspirações distintas, estes puderam ser analisados fora do contexto em que foram desenvolvidos, além de trazer visões diferentes ou até mesmo contrastantes entre as produções de cada um dos alunos, entendendo também as diferenças e semelhanças entre os trabalhos.

Como lacuna da pesquisa a ser abordada futuramente está à estrutura da avaliação do trabalho, através do levantamento de referencial bibliográfico do auto avaliação dos discentes como ferramenta de trabalhar a colaboração em sala de aula nos cursos de graduação. As experiências dos trabalhos relatados apontam que o caminho para promover a reflexão acerca do processo criativo, desenvolvimento coletivo e análise sistêmica em sala de aula é possível como pensamento reflexivo nos processos participativos de todos os atores dos projetos. Além disso, essa experiência possibilitou gerar reflexões nos alunos de sua atuação no processo de aprendizado. Os autores compreendem a contribuição deste estudo para a área, contudo acreditam que não se esgotam aqui as pesquisas possíveis e aplicações de trabalhos em sala de aula com a intenção de desenvolver esse levantamento e análise dos resultados, indicando a possibilidade de futuros trabalhos.

\section{Agradecimentos}

Aos professores que participaram do processo de maturação desse artigo, pelas preciosas contribuições e inspirações. Aos alunos da graduação de Bacharelado em Design e tecnologia em Design Gráfico pela ativa participação e dedicação às atividades propostas. Ao povo brasileiro, representado institucionalmente pela CAPES, pelo apoio financeiro.

\section{Referências}

ANSASTASSAKIS, Z. PAES, L. Reflexões sobre processos colaborativos de design In: Congresso Brasileiro de Pesquisa e Desenvolvimento em Design, 12, Belo Horizonte, 2016. Anais do 120 Congresso Brasileiro de Pesquisa e Desenvolvimento em Design. São Paulo, 2016. p. 936-946.

BAUDRILLARD, J. Simulacros e simulações. Lisboa: Relógio d'Água, 1991.

BAUMAN, Zygmunt. Modernidade Líquida. Rio de Janeiro: Jorge Zahar, 2001

CAMPI, I. La historia y las teorias historiográficas del diseño. México, D. F.: Editorial Designio, 2003.

CARDOSO, Rafael. Uma introdução à história do design. São Paulo: Edgard Blücher, 2008.

CONFORTO, E. C.; AMARAL, D. C.; DA SILVA, S. L. Roteiro para revisão bibliográfica sistemática: aplicação no desenvolvimento de produtos e gerenciamento de projetos. $8^{\circ}$ Congresso Brasileiro de Gestão de Desenvolvimento de Produto, Porto Alegre, 2011.

FORTY, A. Objetos de desejo: design e sociedade desde 1750. São Paulo: Cosac Naify, 2007.

GRUSZYNSKI, Ana Cláudia. Design Gráfico: do Invisível ao llegível. 1. ed. Rio de Janeiro: $2 A B, 2000$. 
HEEMANN, A.; LIMA, P. J. V.; CORRÊA, J. S. Fundamentos para o alcance da colaboração em design. In: Congresso Brasileiro de Pesquisa e Desenvolvimento em Design, 8, São Paulo, 2008. Anais do 80 Congresso Brasileiro de Pesquisa e Desenvolvimento em Design. São Paulo, 2008. p. 1338-1349.

HEEMANN, A.; LUGLI, D. Human-centered design e student-centered learning: projetando para a experiência da educação. In: Congresso Brasileiro de Pesquisa e Desenvolvimento em Design, 12, Belo Horizonte, 2016. Anais do 120 Congresso Brasileiro de Pesquisa e Desenvolvimento em Design. São Paulo, 2016. p. 2200-2211.

SANTOS, Marinês Ribeiro dos. Questionamentos sobre a oposição marcada pelo gênero entre produção e consumo no design moderno brasileiro: Georgia Hauner e a empresa de móveis Mobilinea (1962-1975). Caderno a Tempo: Histórias em arte e design. Barbacena: EdUEMG, vol.2, 2015, p.25-45. 